\title{
ST
}

Science \& Technology

PAPER - OPEN ACCESS

\section{Peningkatan Hasil Belajar Siswa dengan Pembelajaran Kooperatif dan Penggunaan Media Animasi Komputer}

\author{
Author : Wardatul Irham dkk., \\ DOI $\quad: 10.32734 /$ st.v2i1.350 \\ Electronic ISSN $\quad: 2654-7082$ \\ Print ISSN : :2654-7074
}

Volume 2 Issue 1 - 2018 TALENTA Conference Series: Science \& Technology (ST)

This work is licensed under a Creative Commons Attribution-NoDerivatives 4.0 International License.

Published under licence by TALENTA Publisher, Universitas Sumatera Utara

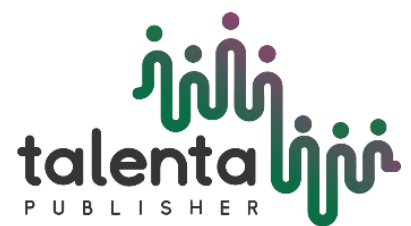




\title{
jiditi talentaliois \\ TM Conference Series 02 (2019)
}

P U B L I S HER

\section{Peningkatan Hasil Belajar Siswa dengan Pembelajaran Kooperatif dan Penggunaan Media Animasi Komputer}

Available online at https://talentaconfseries.usu.ac.id

\author{
Wardatul Husna Irham ${ }^{\mathrm{a}}$ dan Mahmud ${ }^{\mathrm{b}}$
}

\author{
${ }^{a}$ Mahasiswa Program Doktor Kimia Pasca Sarjana FMIPA Universitas Sumatera Utara, Dosen Universitas Sains Cut Nyak Dhien Langsa \\ ${ }^{b}$ Dosen Pasca Sarjana Universitas Negeri Medan
}

\begin{abstract}
Abstrak
Pembelajaran kooperatif merupakan sekumpulan strategi mengajar yang digunakan guru agar siswa saling membantu dalam mempelajari sesuatu. Oleh karena itu belajar kooperatif ini juga dinamakan "belajar teman sebaya." Menurut Slavin [1], pembelajaran kooperatif, merupakan metode pembelajaran dengan siswa bekerja dalam kelompok yang memiliki kemampuan heterogen. Penelitian Situmorang [2] menunjukkan bahwa inovasi pembelajaran menggunakan media komputer dapat meningkatkan prestasi belajar mahasiswasebesar $82 \%$ dan meningkatkan daya ingat terhadap penguasaan materi pelajaran dibandingkan terhadap pembelajaran dengan menggunakan metode ceramah. Penelitian ini bertujuan untuk mendapatkan hasil yang optimal dalam penggunaan strategi pembelajaran kooperatif dengan media animasi komputer pada pelajaran kimia. Metode penelitian adalah metode eksperimen. Instrumen penelitian telah diuji validitas, daya beda, tingkat kesukaran dan reliabilitas. Teknik analisis yang digunakan teknik Analisis varians satu jalur (One Way Anova). Hasil penelitian menunjukkan hasil belajar kimia siswa menggunakan pembelajaran kooperatif yang diintegrasikan dengan media animasi komputer lebih baik secara signifikan.
\end{abstract}

Kata Kunci : Peningkatan hasil belajar, pembelajaran kooperatif, stoikiometri, eksperimen

\section{Pendahuluan}

Kurangnya variasi metode dan strategi sistem pengajaran dapat membuat siswa merasa kesulitan dalam memahami pelajaran tersebut, maka perlu dilakukan satu model strategi pembelajaran yang baik. Strategi merupakan usaha untuk memperoleh kesuksesan dan keberhasilan dalam mencapai tujuan. Dalam dunia pendidikan strategi dapat diartikan sebagai suatu perencanaan, metode, atau langkah-langkah disain pembelajaran untuk mencapai tujuan pembelajaran (a plan, method, or series of activities designed to achieves a particular educational goal). Pengertian Strategi pembelajaran cukup beragam walaupun pada dasarnya sama. Strategi adalah suatu prosedur yang digunakan untuk memberikan suasana yang konduktif kepada siswa dalam rangka mencapai tujuan pembelajaran.

Model pembelajaran kooperatif memungkinkan semua siswa dapat menguasai materi pada tingkat penguasaan yang relatif sama atau sejajar. Pembelajaran kooperatif telah dikembangkan secara intensif melalui berbagai penelitian, tujuannya untuk meningkatkan kerjasama akademik antar siswa, membentuk hubungan positif, mengembangkan rasa percaya diri, serta meningkatkan kemampuan akademik melalui aktivitas kelompok. Dalam penelitian tersebut terbukti bahwa dalam pembelajaran kooperatif terdapat saling ketergantungan positif di antara siswa untuk mencapai tujuan pembelajaran. Melalui interaksi belajar yang efektif siswa menjadi lebih termotivasi, lebih percaya diri, mampu menggunakan strategi berpikir tingkat tinggi, serta mampu membangun hubungan interpersonal.

Menurut Slavin [1], pembelajaran kooperatif, merupakan metode pembelajaran dengan siswa bekerja dalam kelompok yang memiliki kemampuan heterogen. Pembelajaran kooperatif atau cooperative learning mengacu pada 
metode pengajaran, siswa bekerja bersama dalam kelompok kecil saling membantu dalam belajar. Sanjaya [3] menyatakan bahwa "pembelajaran kooperatif merupakan model pembelajaran dengan menggunakan sistem pengelompokan/kelompok kecil, yaitu antara empat sampai enam orang yang mempunyai latar belakang kemampuan akademik, jenis kelamin, ras, atau suku yang berbeda (heterogen)". Sistem penilaian dilakukan terhadap kelompok. Setiap kelompok akan memperoleh penghargaan (reward), jika kelompok mampu menunjukkan prestasi yang dipersyaratkan. Dengan demikian, setiap anggota kelompok akan mempunyai ketergantungan positif.

Beberapa media pendidikan yang sering digunakan dalam proses belajar mengajar diantaranya media cetak, elektronik, sketsa, model, peta dan diagram [4]. Media elektronik seperti video banyak digunakan dalam pembelajaran sains, untuk membantu pembelajaran terutama untuk memberikan penekanan pada meteri pelajaran yang sangat penting diketahui siswa. Penyampaian materi pelajaran dengan menggunakna media ini bertujuan meningkatkan penguasaan materi kimia sehingga penyampaian materi pelajaran terkesan tidak membosankan [5]. Media komputer merupakan media yang menarik bahkan atraktif dan interaktif. Pembelajaran dengan menggunakan media komputer sesungguhnya membekalkan pada setiap orang dengan berbagai karakter yang menjadi kekuatan dan kelemahan suatu media [6].

Berdasarkan uraian diatas, maka dianggap perlu dilakukan suatu perubahan cara mengajar kimia melalui suatu strategi pembelajaran unggul yang dapat membangkitkan motivasi, daya kreativitas dan semangat belajar siswa agar mencapai hasil belajar yang memuaskan. model pembelajaran kooperatif mempunyai kekuatan dalam mengembangkan softskills siswa, seperti: kemampuan berkomunikasi, berfikir kritis, bertanggung jawab, serta bekerja sama. Jika kelemahan dapat diminimalkan, maka kekuatan model ini akan membuahkan proses dan hasil belajar yang dapat memacu peningkatan potensi siswa secara optimal.

\section{Metode}

Populasi dan Sampel. Sebagai populasi dalam penelitian ini adalah siswa kelas X Madrasah Aliyah Negeri Binjai yang berjumlah delapan (8) kelas. Sampel dalam penelitian ini adalah siswa kelas X Madrasah Aliyah Negeri Binjai yang diambil sebanyak 3 kelas yang dianggap memiliki kemampuan yang sama. Pengambilan sampel ini berdasarkan beberapa pertimbangan dan tujuan tertentu yang dapat mewujudkan tujuan penelitian ini.

Variabel Penelitian. Dalam penelitian ini terdapat dua variabel, yaitu variabel bebas (X) dan variabel terikat (Y). Variabel bebas dalam penelitian ini adalah pembelajaran konvensional $\left(\mathrm{X}_{1}\right)$, pembelajaran kooperatif tanpa media animasi komputer $\left(\mathrm{X}_{2}\right)$ dan pembelajaran kooperatif yang diintegrasikan dengan media animasi komputer $\left(\mathrm{X}_{3}\right)$. Sedangkan variabel terikatnya adalah hasil belajar siswa (Y).

Jenis Penelitian. Penelitian ini bersifat eksperimen, dengan membuat perlakuan dengan memberikan pengajaran menggunakan model pembelajaran Kooperatif dan penggunaan animasi komputer dibandingkan dengan pengajaran secara konvensional ceramah.

Desain Penelitian. Penelitian ini melibatkan 3 kelas eksperimen yang diberi perlakuan yang berbeda. Pada kelas eksperimen 1 diberi perlakuan kontrol yaitu pembelajaran konvensional, pada kelas eksperimen 2 diberi perlakuan pembelajaran kooperatif tanpa penggunaan media animasi komputer, dan pada kelas eksperimen 3 diberi perlakuan pembelajaran kooperatif dengan penggunaan media animasi komputer. Untuk melihat hasil belajar siswa pada eksperimen ini, diberikan tes pada siswa sebelum perlakuan eksperimen (pretest) dan setelah perlakuan eksperimen (postest). Untuk lebih jelasnya disain penelitian ini ditunjukkan pada Tabel 1 dan diagram alir penelitian pada gambar 1. 
Tabel 1. Disain penelitian

\begin{tabular}{cccc}
\hline Kelas & Pre Test & Perlakuan & Post Test \\
\hline Kelas Eksperimen 1 & $\mathrm{Y}_{1.1}$ & $\mathrm{X}_{1}$ & $\mathrm{Y}_{2.1}$ \\
\hline Kelas Eksperimen 2 & $\mathrm{Y}_{1 \cdot 2}$ & $\mathrm{X}_{2}$ & $\mathrm{Y}_{2.2}$ \\
\hline Kelas Eksperimen 3 & $\mathrm{Y}_{1.3}$ & $\mathrm{X}_{3}$ & $\mathrm{Y}_{2.3}$ \\
\hline
\end{tabular}

\section{Keterangan :}

$\mathrm{Y}_{1.1}$ : Hasil pretest pada kelas eksperimen 1

$\mathrm{Y}_{1.2}$ : Hasil pretest pada kelas eksperimen 2

$\mathrm{Y}_{1.3} \quad$ : Hasil pretest pada kelas eksperimen 3

$\mathrm{X}_{1}$ : Perlakuan kontrol dengan pembelajaran konvensional

$\mathrm{X}_{2}$ : Perlakuan pembelajaran koperatif tanpa media animasi komputer

$\mathrm{X}_{3}$ : Perlakuan pembelajaran koperatif yang diintegrasikan dengan media animasi komputer

$\mathrm{Y}_{2.1}$ : Hasil postest pada kelas eksperimen 1

$\mathrm{Y}_{2.2}$ : Hasil postest pada kelas eksperimen 2

$\mathrm{Y}_{2.3}$ : Hasil postest pada kelas eksperimen 3

Instrumen Penelitian. Instrumen yang digunakan dalam penelitian ini berupa tes dengan bentuk pilihan berganda. Tes hasil belajar diberikan diawal kegiatan perlakuan dan diakhir kegiatan perlakuan. Tes dibuat berdasarkan kisi-kisi yang sesuai dengan definisi operasional. Tes tersebut sesuai dengan kurikulum KTSP SMU, buku pegangan guru dan siswa. Sebelum tes digunakan, terlebih dahulu ditinjau validitas isinya melalui uji validitas tes dan pendapat para ahli sebagai validator.

Tes hasil belajar digunakan untuk mengukur penguasaan dan kemampuan yang dicapai seseorang dalam berbagai bidang pengetahuan. Tes adalah serentetan pertanyaan yang digunakan untuk mengukur pengetahuan intelegensia atau kemampuan yang dimiliki oleh individu atau kelompok [7]. Dengan demikian instrumen yang digunakan adalah tes kemampuan kognitif dalam bentuk pilihan berganda (multiple choise).

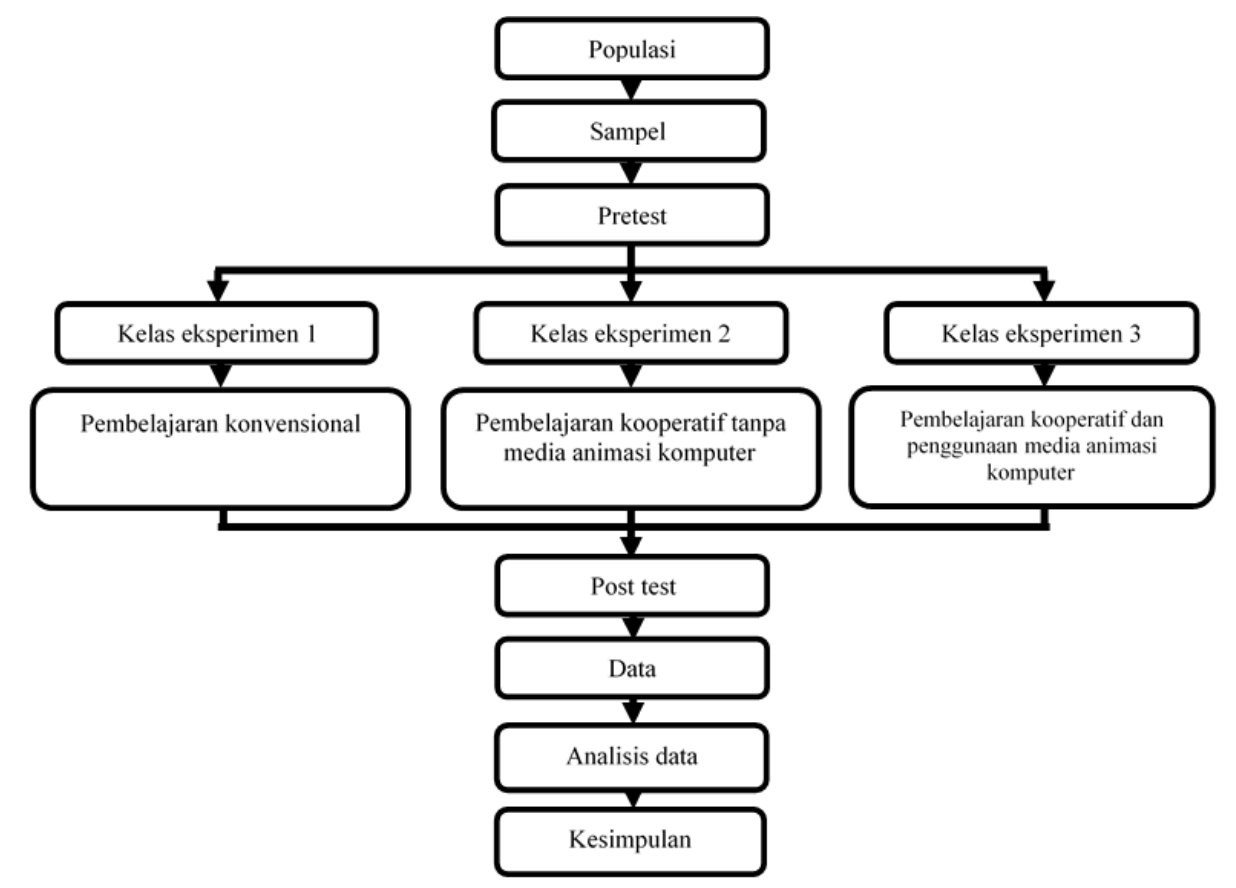

Gambar 1. Diagram Alir Penelitian 


\section{Hasil dan Pembahasan}

Uji hipotesis. Dari hasil uji hipotesis diperoleh data pada tabel 2 dan 3 yaitu :

Tabel 2. Uji Anova

hasil_belajar

\begin{tabular}{l|c|c|c|c|c}
\hline & Jumlah kuadrat & df & Rata-rata kuadrat & F & Sig. \\
\hline Antar kelompok & 4190.8060 & 2 & 2095.4030 & 26.2270 & .0000 \\
Inter kelompok & 6791.0120 & 85 & 79.8940 & & \\
Total & 10981.8180 & 87 & & & \\
\hline
\end{tabular}

Tabel 3. Kriteria penerimaan hipótesis

\begin{tabular}{|c|c|c|c|c|c|c|}
\hline \multirow{2}{*}{ (I) eksperimen } & \multirow{2}{*}{ (J) eksperimen } & \multirow{2}{*}{$\begin{array}{l}\text { Beda rata- } \\
\text { rata }(\mathrm{I}-\mathrm{J})\end{array}$} & \multirow{2}{*}{$\begin{array}{l}\text { Std. } \\
\text { Error }\end{array}$} & \multirow[b]{2}{*}{ Sig. } & \multicolumn{2}{|c|}{ Tingkat kepercayaan 95\% } \\
\hline & & & & & Bawah & Atas \\
\hline \multirow[t]{2}{*}{$\begin{array}{l}\text { pembelajaran } \\
\text { konvensional }\end{array}$} & $\begin{array}{l}\text { pembelajaran kooperatif tanpa media animasi } \\
\text { komputer }\end{array}$ & $-7.4405^{*}$ & 2.34872 & .0020 & -12.1104 & -2.7706 \\
\hline & $\begin{array}{l}\text { pembelajaran kooperatif yang diintegrasikan dengan } \\
\text { media animasi komputer }\end{array}$ & $-16.9405^{*}$ & 2.3487 & .0000 & -21.6104 & -12.2706 \\
\hline \multirow{2}{*}{\multicolumn{2}{|c|}{$\begin{array}{l}\text { pembelajaran kooperatif pembelajaran konvensional } \\
\text { tanpa media animasi } \\
\begin{array}{ll}\text { komputer } & \text { pembelajaran kooperatif yang diintegrasikan dengan } \\
& \text { media animasi komputer }\end{array}\end{array}$}} & $7.4405^{*}$ & 2.3487 & .0020 & 2.7706 & 12.1104 \\
\hline & & $-9.5000^{*}$ & 2.3079 & .000 & -14.0887 & -4.9113 \\
\hline \multirow{2}{*}{\multicolumn{2}{|c|}{$\begin{array}{ll}\text { pembelajaran kooperatif pembelajaran konvensional } \\
\text { yang diintegrasikan } & \\
\text { dengan media animasi } & \text { pembelajaran kooperatif tanpa media animasi } \\
\text { komputer } & \text { komputer }\end{array}$}} & $16.9405^{*}$ & 2.3487 & .0000 & 12.2706 & 21.6104 \\
\hline & & $9.5000^{*}$ & 2.3079 & .0000 & 4.9113 & 14.0887 \\
\hline
\end{tabular}

*. The mean difference is significant at the 0.05 level.

Dari tabel 2 dapat dilihat bahwa pada data hasil belajar memiliki jumlah kuadrat antar kelompok sebesar 4190,8060; inter kelompok sebesar 6791,0120 dan total sebesar 10981,8180 dengan df antar kelompok sebesar 2, inter kelompok sebesar 85 dan total sebesar 87. Rata-rata kuadrat antar kelompok sebesar 2095,4030 dan inter kelompok sebesar 79,8940. Nilai F sebesar 26,2270 dan nilai signifikan sebesar 0,0000 yang data ini memiliki nilai yang signifikan pada taraf 0,05 .

Dari tabel 3 dapat dilihat perbedaan nilai rata-rata eksperimen 2 dan eksperimen 1 sebesar -7,4405 dengan estándar error 2,3487; nilai signifikan 0,0020; tingkat kepercayaan 95\% terendah pada $-12,1104$ tertinggi pada 2,7706. Perbedaan nilai rata-rata eksperimen 3 dan eksperimen 1 sebesar -16.9405 dengan stándar error 2,3487; nilai signifikan 0,0000; tingkat kepercayaan 95\% terendah pada -21,6104 tertinggi pada -12,2706.

Perbedaan nilai rata-rata eksperimen 1 dan eksperimen 2 sebesar 7,4405 dengan stándar error 2,3487; nilai signifikan 0,0020; tingkat kepercayaan $95 \%$ terendah pada 2,7706 tertinggi pada 12,1104 . Perbedaan nilai rata-rata eksperimen 3 dan eksperimen 2 sebesar -9,5000 dengan estándar error 2,3079; nilai signifikan 0,0000; tingkat kepercayaan $95 \%$ terendah pada $-14,0887$ tertinggi pada $-4,9113$.

Perbedaan nilai rata-rata eksperimen 1 dan eksperimen 3 sebesar 16.9405 dengan stándar error 2,3487; nilai signifikan 0,0000; tingkat kepercayaan 95\% terendah pada 12,2706 tertinggi pada 21,6104. Perbedaan nilai rata-rata eksperimen 2 dan eksperimen 3 sebesar 9,5000 dengan stándar error 2,3079; nilai signifikan 0,0000; tingkat kepercayaan $95 \%$ terendah pada 4,9113 tertinggi pada 14,0887. 
Hipotesis penelitian ini adalah :1) Pada tabel kriteria penerimaan hipotesis dapat kita lihat bahwa antara $\mathrm{X}_{3}$ dan $\mathrm{X}_{2}$ memiliki nilai sig 0,0000 yang lebih kecil dari 0,05. Hal ini berarti bahwa Ho ditolak dan Ha diterima. Kesimpulan ini diperkuat dengan adanya tanda $(*)$ pada beda rata-rata yang menunjukkan penerimaan Ha secara signifikan. Maka dapat dirumuskan bahwa " Hasil belajar kimia siswa menggunakan pembelajaran kooperatif yang diintegrasikan dengan media animasi komputer lebih baik secara signifikan dari hasil belajar siswa menggunakan pembelajaran kooperatif tanpa media animasi komputer".2)Pada tabel kriteria penerimaan hipotesis dapat kita lihat bahwa antara $\mathrm{X}_{3}$ dan $\mathrm{X}_{1}$ memiliki nilai sig 0,0000 yang lebih kecil dari 0,05. Hal ini berarti bahwa Ho ditolak dan Ha diterima. Kesimpulan ini diperkuat dengan adanya tanda $(*)$ pada beda rata-rata yang menunjukkan penerimaan Ha secara signifikan. Maka dapat dirumuskan bahwa "Hasil belajar kimia siswa menggunakan pembelajaran kooperatif yang diintegrasikan dengan media animasi komputer lebih baik secara signifikan dari hasil belajar siswa menggunakan metode konvensional".3)Pada tabel kriteria penerimaan hipotesis dapat kita lihat bahwa antara $\mathrm{X}_{2}$ dan $\mathrm{X}_{1}$ memiliki nilai sig 0,0020 yang lebih kecil dari 0,05. Hal ini berarti bahwa Ho ditolak dan Ha diterima. Kesimpulan ini diperkuat dengan adanya tanda (*) pada beda rata-rata yang menunjukkan penerimaan Ha secara signifikan. Maka dapat dirumuskan bahwa "Hasil belajar kimia siswa menggunakan pembelajaran kooperatif tanpa media animasi komputer lebih baik secara signifikan dari hasil belajar siswa menggunakan metode konvensional".4)Pada tabel anova dapat kita lihat bahwa nilai sig 0,0000 yang lebih kecil dari 0,05 . Hal ini berarti bahwa Ho ditolak dan Ha diterima secara signifikan. Maka dapat dirumuskan bahwa "Hasil belajar kimia siswa menggunakan pembelajaran kooperatif yang diintegrasikan dengan media animasi komputer lebih baik secara signifikan dari hasil belajar siswa menggunakan pembelajaran kooperatif tanpa media animasi komputer dan lebih baik secara signifikan dari hasil belajar siswa menggunakan metode konvensional".

\section{Kesimpulan}

Berdasarkan data-data yang diperoleh yang kemudian diuji dengan sistem pengolahan data, maka dapat diambil beberapa kesimpulan dalam penelitian ini, yaitu sebagai berikut :

1. Hasil belajar kimia siswa menggunakan pembelajaran kooperatif yang diintegrasikan dengan media animasi komputer lebih baik secara signifikan dari hasil belajar siswa menggunakan pembelajaran kooperatif tanpa media animasi komputer.

2. Hasil belajar kimia siswa menggunakan pembelajaran kooperatif yang diintegrasikan dengan media animasi komputer lebih baik secara signifikan dari hasil belajar siswa menggunakan metode konvensional.

3. Hasil belajar kimia siswa menggunakan pembelajaran kooperatif tanpa media animasi komputer lebih baik secara signifikan dari hasil belajar siswa menggunakan metode konvensional.

4. Hasil belajar kimia siswa menggunakan pembelajaran kooperatif yang diintegrasikan dengan media animasi komputer lebih baik secara signifikan dari hasil belajar siswa menggunakan pembelajaran kooperatif tanpa media animasi komputer dan lebih baik secara signifikan dari hasil belajar siswa menggunakan metode konvensional.

\section{Referensi}

[1] Slavin, R, E. 2005. Cooperative Learning Teori, Riset dan Praktek. Massachusetts: Allymand Bacon Publisher. Bandung. Penerbit Nusa Media.

[2] Situmorang, M., 2006. Efektifitas Inovasi Pembelajaran Untuk Meningkatkan Prestasi Belajar Mahasiswa Dalam Perkuliahan Kimia Analitik-II, Jurnal Penelitian bidan g Pendidikan 13(1): 1-13.

[3] Sanjaya, W., 2006, Strategi Pembelajaran Berorientasi Standar Proses Pendidikan, Jakarta: Kencana Prenada Media Group.

[4] Arends, R. I., 2001. Learning to Teach. New York: McGraw Hill Companies.

[5] Situmorang, M., dan Silitonga, L.L., 2009. Efektifitas Media Audiovisual Terhadap Peningkatan Prestasi Relajar Siswa pada Pengajaran Sistem Koloid, Jurnal Pendidikan Nimia 1(1): 1-3.

[6] Munir, 2008. Kurikulum Berbasis Teknologi Informasi dan Komunikasi. Bandung. Alfabeta

[7] Arikunto, S., 2002. Dasar-dasar Evaluasi Pendidikan (edisi revisi) . Jakarta: Bumi Aksara 